\title{
Periodontal inflamed surface area in patients on haemodialysis and peritoneal dialysis: a Croatian cross-sectional study
}

\author{
Bojana Križan Smojver ${ }^{1 *}$, Karmela Altabas ${ }^{2}$ Mladen Knotek ${ }^{3}$, Nikolina Bašić Jukić ${ }^{4}$ and Andrej Aurer ${ }^{5}$
}

\begin{abstract}
Background: The decision to initiate dialysis treatment via haemodialysis (HD) or peritoneal dialysis (PD) often involves the consideration of complex factors and remains a matter of debate. The purpose of this study was to quantify the inflammatory burden that periodontitis causes in dialysis patients and to examine whether patients on PD and HD differ in terms of the periodontal inflamed surface area (PISA), which can be helpful for selecting the most appropriate dialysis modality.
\end{abstract}

Methods: A cross-sectional study was performed on 58 consecutive patients on HD and 31 consecutive patients on PD. PISA was calculated using measurements of the clinical attachment level, recession and bleeding on probing. We performed the primary analysis using multivariable robust regression.

Results: Patients on PD had a $746 \mathrm{~mm}^{2}$ (93\%) lower mean PISA than patients on HD after adjustment for 20 possible confounders, including the duration of dialysis. The type of dialysis was independently correlated with the PISA (semipartial correlation: $-0.50 ; p=0.017$; false discovery rate $<5 \%$ ). After adjusting for confounding factors, the correlation between the duration and type of dialysis was not significant $\left(F(2,44)=0.01 ; p=0.994 ; \eta^{2}=0.00\right)$. Differences in the PISA between patients who had undergone dialysis for less than a year, 2-3 years or $\geq 3$ years were not significantly different in either of the two dialysis groups.

Conclusions: PISA levels in Croatian patients on dialysis indicate a high need for periodontal treatment. PD is associated with a smaller PISA independent of many sociodemographic, lifestyle, laboratory and clinical factors. The duration of dialysis does not influence PISA levels.

Trial registration: ISRCTN17887630.

A clinical study to investigate gum infection in patients undergoing kidney dialysis.

Keywords: Periodontitis, PISA, Peritoneal dialysis, Haemodialysis, Kidney failure

\footnotetext{
* Correspondence: bojana.krizan@gmail.com

'Department of Endodontics with Restorative Dentistry, Oral Medicine and

Periodontology, Dental Clinic Zagreb, Perkovčeva ulica 3, 10000 Zagreb,

Croatia

Full list of author information is available at the end of the article
}

(C) The Author(s). 2020 Open Access This article is licensed under a Creative Commons Attribution 4.0 International License, which permits use, sharing, adaptation, distribution and reproduction in any medium or format, as long as you give appropriate credit to the original author(s) and the source, provide a link to the Creative Commons licence, and indicate if changes were made. The images or other third party material in this article are included in the article's Creative Commons licence, unless indicated otherwise in a credit line to the material. If material is not included in the article's Creative Commons licence and your intended use is not permitted by statutory regulation or exceeds the permitted use, you will need to obtain permission directly from the copyright holder. To view a copy of this licence, visit http://creativecommons.org/licenses/by/4.0/ The Creative Commons Public Domain Dedication waiver (http://creativecommons.org/publicdomain/zero/1.0/) applies to the data made available in this article, unless otherwise stated in a credit line to the data. 


\section{Background}

Chronic kidney disease (CKD) is defined as kidney damage or a glomerular filtration rate (GFR) of $<60 \mathrm{~mL} /$ $\min / 1.73 \mathrm{~m}^{2}$ for 3 months or more, irrespective of the cause [1]. The loss of kidney functions leads to the accumulation of metabolic waste products that have an impact on the patient's body. There are five CKD stages according to the estimated glomerular filtration rate (eGFR), and the last stage is end-stage renal disease (ESRD) or kidney failure (eGFR $<15 \mathrm{ml} / \mathrm{min} / 1.73 \mathrm{~m}$ ) [1]. Kidney transplantation is the treatment of choice for improved survival of ESRD patients, but when transplantation is not possible either due to the medical condition of the patient or lack of available organs, dialysis is a viable mode of treatment. There are two main types of dialysis: haemodialysis (HD) and peritoneal dialysis (PD). The decision to initiate dialysis treatment using haemodialysis or peritoneal dialysis is often complex and remains a matter of debate [2]. Although it has been shown that PD can provide similar or better survival rates and better quality of life and that PD is more economical than HD, in 2008, there were only 196,000 PD patients comprising $11 \%$ of the global dialysis population [3].

Periodontitis is a bacteria-driven chronic inflammatory disease that destroys the connective tissue and bone that support the teeth. Periodontitis represents a potential source of episodes of bacteraemia, especially in immune compromised patients [4]. Severe periodontitis is the 6th most prevalent disease worldwide, with an overall prevalence of $11.2 \%$ and approximately 743 million people affected [5].

Its impact on general health status is becoming increasingly apparent [6]. Periodontitis causes inflammation, systemic inflammatory responses or cross-reactivity that may lead to autoimmune reactions [7]. Researchers have reported that periodontitis poses an increased risk for various chronic diseases, such as coronary heart disease and stroke, diabetes, respiratory diseases and osteoporosis, as well as preterm low-birth-weight infants [8]. Furthermore, it contributes to systemic diseases due to an increased inflammatory burden [9]. Periodontitis can lead to systemic dispersal (via the bloodstream) of some locally produced pro-inflammatory mediators (e.g., IL-1b, IL- 6 and TNF- $\alpha$ ). Cytokines can stimulate the immune system, modify lipid metabolism and increase cytokine-mediated inflammatory processes (C-reactive protein), leading to further systemic conditions, such as endothelial dysfunction, atherosclerosis, coronary artery disease and glomerulonephritis. Moreover, it has been reported that periodontal bacteria can invade endothelial cells. A recent meta-analysis confirmed the association between CKD and periodontal disease and that the strength of this association was increased when severe periodontitis was considered [10]. Periodontitis thus represents an often overlooked problem in CKD patients. Lack of oral health management may contribute to systemic consequences, such as inflammation, infection, protein-energy wasting and atherosclerotic complications, which can contribute to increased morbidity and mortality [11]. The risk of systemic complications is probably higher if the surface of inflamed periodontal tissue is large. The periodontal inflamed surface area (PISA) represents the surface area in square millimetres of the bleeding pocket epithelium for all teeth. It is also advantageous for data processing and analysis because it can be treated as a continuous variable to quantify periodontal inflammation [12].

The aim of this study was to quantify the inflammatory burden that periodontitis poses in dialysis patients and to examine whether patients on PD and HD differ according to their PISA, which can be helpful in selecting the most appropriate dialysis modality. The main hypothesis put forth in this study is that PD is associated with a lower PISA.

\section{Methods \\ Study design}

A cross-sectional study including 58 consecutive patients on HD and 31 consecutive patients on PD was conducted. Patients were treated at the Department of Internal Medicine, University Hospital Center "Sestre milosrdnice", Zagreb, Croatia, between February 2015 and January 2016. The study protocol was approved by the ethics committees of the Hospital and of the School of Dental Medicine, University of Zagreb. All patients gave written informed consent for participation. The study was performed in accordance with the World Medical Association Declaration of Helsinki [13].

\section{Participants}

The targeted populations were patients of both genders, $\geq 18$ years old, who were diagnosed with CKD (stage V) and treated with HD or PD. The exclusion criteria were an age $<18$ years, level I-IV renal failure, renal transplant patients, having received periodontal treatment within the last 6 months, receiving antibiotic treatment at the time of examination and the presence of fewer than 8 teeth. We selected a consecutive sample of patients by the order of their dialysis initiation.

\section{Required sample size}

The required sample size was calculated before the start of enrolment based on a pilot study performed on a sample of 20 patients on HD and 10 patients on PD during 2013. These patients were not included in the present study. A sample size of 70 patients achieved $80 \%$ power to detect an $R^{2} \geq 0.10$ attributed to the type of dialysis using an F-test with a significance level of $p \leq$ 
0.05 , after adjusting for 15 possible confounders whose association with PISA was $R^{2}=0.20$. The ratio of the size of the two groups was determined to be 2:1 with respect to the sizes of the populations of patients treated with the two types of dialysis. Expecting up to 20\% of responders to have missing data, the initially needed sample size was determined to be $n=74$. A power analysis was performed using PASS 14 Power Analysis and Sample Size Software (2015; NCSS, LLC, Kaysville, Utah, USA).

\section{Outcomes}

The main outcome was PISA, which was calculated based on BOP, CAL and REC measurements that were performed at six sites on each tooth using a periodontal probe (PCP 15; Hu-Friedy, Chicago, IL, USA). All periodontal examinations were performed by the same calibrated examiner.

PISA was calculated by the on-line calculator available at www.parsprototo.info [12]. Using the formulas described by Hujoel et al. [14], a Microsoft Excel spreadsheet was constructed to facilitate the PISA calculation [12]. PISA was calculated in seven steps: 1) after inputting into Excel the CAL measurements at six sites per tooth, the mean CAL for each particular tooth was calculated; 2) the mean CAL around a particular tooth was entered into the appropriate formula for the translation of linear CAL measurements to the attachment loss surface area (ALSA) for that specific tooth; 3) after filling in the REC measurements at six sites per tooth, the mean REC was calculated for each particular tooth; 4) the mean REC around a particular tooth was entered into the appropriate formula for the translation of linear REC measurements to the REC surface area (RSA) for that tooth; 5) the RSA for the specific tooth was subtracted from the ALSA of that tooth, rendering the periodontal epithelial surface area (PESA) of the tooth $(\mathrm{PESA}=\mathrm{ALSA}-\mathrm{RSA}) ; 6)$ the PESA for the tooth was then multiplied by the proportion of sites around the tooth affected by BOP; for example, if three of the maximum of six sites were affected by BOP, the PESA of that particular tooth was multiplied by $3 / 6$, thereby rendering the PISA for the tooth; and 7) the sum of all individual PISAs around individual teeth was calculated, amounting to the total PISA within a patient's mouth [7]. The independent variable was HD or PD.

\section{Possible confounding variables controlled by the multivariable analysis}

Based on the literature and previous studies, before the start of analysis, 15 variables were selected with possible confounding effects: 1) age; 2) duration of dialysis in months; 3) number of teeth; 4) smoking; 5) C-reactive protein; 6) dialysis adequacy measured by the ratio between dialyser clearance $(\mathrm{K})(\mathrm{mL} / \mathrm{min})$ multiplied by time in minutes $(\mathrm{t})$ and the volume of water a patient's body contains (Kt/V); 7) thrombocytes; 8) urea; 9) phosphorus; 10) high-density lipoprotein (HDL) cholesterol; and treatment with 11) beta-blockers, 12) angiotensinconverting enzyme inhibitors, 13) central $\alpha-2$ receptor agents, 14) angiotensin II AT1-receptor blockers, and 15) $\alpha_{1}$-adrenoceptor antagonists. We also controlled five additional possible confounders: diabetes mellitus, duration of diabetes, glycated haemoglobin (HbA1c), leukocytes, and the last visit to the dentist.

\section{Other variables used to describe the two samples}

Other variables used to describe the two samples were gender; education; alcohol consumption; body mass index $\left(\mathrm{kg} / \mathrm{m}^{2}\right)$; arterial hypertension; dry mouth; number of daily tooth-brushing episodes; usage of interdental brushes/floss; self-reported bleeding gums; treatment with calcium channel blocker, antiplatelet or immunosuppressive medication; parathyroid hormone; potassium; mean corpuscular volume; total cholesterol; LDL cholesterol, triglycerides; erythrocytes; creatinine; serum albumin; sodium; alkaline phosphatase; haematocrit; and haemoglobin. Information about age, gender, education, smoking habits and consumption of alcohol, xerostomia, self-observed bleeding of gums and oral hygiene habits was obtained by a questionnaire (Additional file 1) that was designed specifically for this study. The data on other variables were obtained from hospital medical records. We did not independently assess the validity and reliability of the medical records data.

\section{Statistical analysis}

The introductory, bivariable analysis was performed using analysis of variance, with Hedge's g and 95\% confidence intervals presented as the measure of the standardized effect size, and the Mann-Whitney U test. The hypothesis was tested using robust regression and iteratively reweighted least squares simultaneously on all 20 variables and the type of dialysis. We checked the main multivariable analysis results using quantile regression and the adjusted medians of PISA. A main multivariable analysis was performed on the per protocol population with list-wise deletion of patients with missing data. Unstandardized and standardized regression coefficients were presented with the t-test statistic with $\mathrm{n}-\mathrm{p}-1$ degrees of freedom, where $\mathrm{p}$ is the total number of parameters in the model, two-tailed statistical significance of multivariable regression coefficients, zero-order Pearson product-moment correlation with PISA ( $\mathrm{r}$ ), and semipartial correlation with PISA after controlling for all other variables (sr). Imputation of missing data was performed only for the sensitivity analysis. Multiple imputation was applied with fully conditional specification of the iterative Markov chain Monte Carlo method 
(data augmentation algorithm) with a maximum of 100 iterations. To minimize the random fluctuation effect, 30 imputed data sets were created. As the HbA1c value was not available for patients who were not diagnosed with diabetes mellitus, we imputed the value of 5.0. We performed a sensitivity analysis by imputing the values of $\mathrm{HbA} 1 \mathrm{c}=4.0$ and 7.0. The inflation of false positives was controlled using the Benjamini-Holchberg method with the false discovery rate (FDR) set at $\leq 5 \%$. The level of statistical significance was set to two-tailed $p<0.05$, and all confidence intervals were set to $95 \%$. The statistical analysis was performed using the $\mathrm{R}$ Development Core Team [15].

\section{Results}

After screening 127 patients, 89 were enrolled, 58 of whom were on HD and 31 of whom were on PD (Fig. 1). The two groups were different with regard to many sociodemographic, vital, lifestyle and clinical characteristics (Table 1). Patients on HD were older, had been on dialysis longer, had fewer teeth, and had less selfreported bleeding of the gums. According to blood count, the largest differences were in $\mathrm{Kt} / \mathrm{V}$ and parathyroid hormone levels. Kt/V was higher in the PD group, and parathyroid hormone was higher in the HD group. There were also relevant differences in C-reactive protein values (higher in the HD group) and in thrombocyte (higher in the PD group) (Table 2).

In the introductory bivariable analysis, PISA was significantly different between the two dialysis groups. The mean PISA (SD) was $738(520.4) \mathrm{mm}^{2}$ in patients on $\mathrm{HD}$ and $470(277.8) \mathrm{mm}^{2}$ in patients on PD $(\mathrm{F}(1,87)=$ 7.12; $p=0.009$; Hedge's $\mathrm{g}=0.59 ; 95 \% \mathrm{CI}-1.04$ to -0.15 ; FDR $<5 \%$ ). The median PISA (IQR) was $624(335-1042)$ $\mathrm{mm}^{2}$ in patients on HD and $401(272-605) \mathrm{mm}^{2}$ in patients on PD (Mann-Whitney test, $\mathrm{U}=634 ; \mathrm{z}=-2.28$; $p=0.022$; the probability that patients on HD had larger PISA values than patients on PD was 65\%). After adjusting for 20 confounding factors, the type of dialysis was found to be significantly associated (FDR $<5 \%$ ) with PISA (Table 3). Patients on PD had a significantly lower PISA. After adjusting for 20 confounding factors, the mean $\left(95 \%\right.$ CI) PISA was $798(681-914) \mathrm{mm}^{2}$ in the HD group and $52(0-417) \mathrm{mm}^{2}$ in the PD group. This 746 $\mathrm{mm}^{2}$ absolute difference represented a 93\% relative difference. The adjusted median PISA was $732 \mathrm{~mm}^{2}$ in the HD group and $190 \mathrm{~mm}^{2}$ in the PD group. This 542 $\mathrm{mm}^{2}$ absolute difference represented a $74 \%$ relative difference. The type of dialysis showed a semipartial correlation with PISA ( $\mathrm{sr}=-0.50, p<0.017$; FDR $<5 \%$ ). The variation in $\mathrm{HbA} 1 \mathrm{c}$ values imputed for patients with no diagnosed diabetes mellitus 4,5 and 7 revealed identical results. A sensitivity analysis was performed by multiple imputation of the missing data of 20 confounding factors. A pooled analysis on 30 data sets with complete (imputed) data revealed very similar results to the result of the per-protocol and complete case (listwise deletion) analyses: patients on PD had a mean (95\% CI) PISA of -613 ( -995 to -232 ); robust regression, $p=$ $0.002)$ and a median $(95 \%$ CI) PISA of -448 ( -887 to 9; quantile regression, $p=0.046$ ). PISA was significantly lower in the PD group regardless of the duration of dialysis (Fig. 2). After adjusting for confounding factors, the interaction between the duration and type of dialysis was not significant $\left(\mathrm{F}(2,44)=0.01 ; p=0.994 ; \eta^{2}=0.00\right)$. Differences in PISA between patients who had been dialysed for less than a year, 2-3 years or $\geq 3$ years were not significantly different in any of the two dialysis groups.

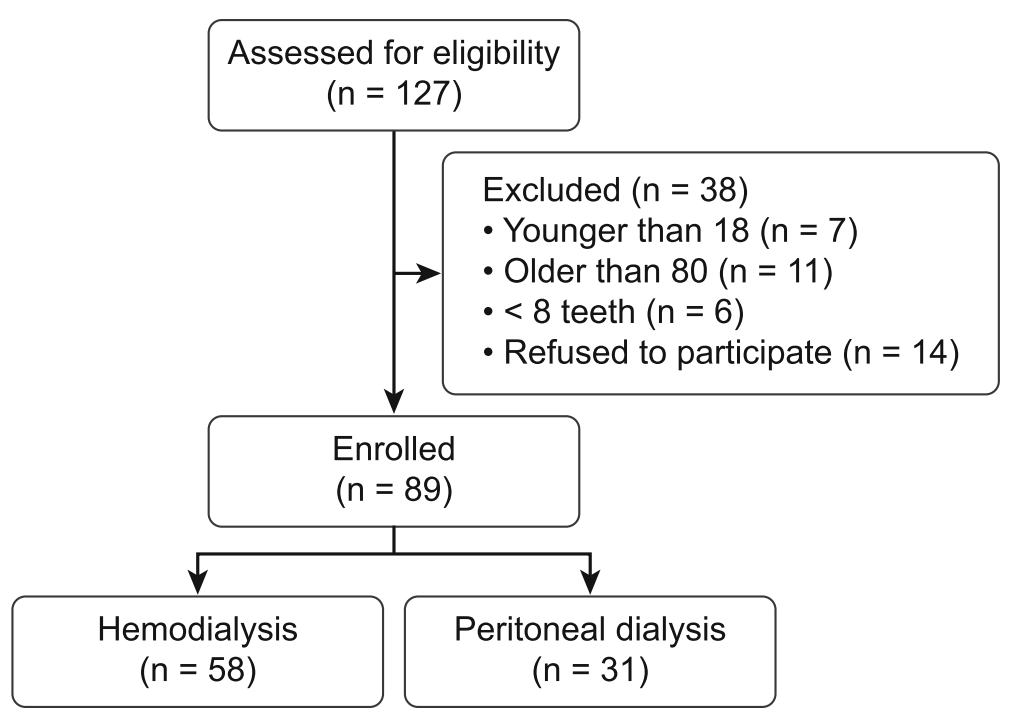

Fig. 1 Patient flow diagram 
Table 1 Patients' sociodemographic, vital, lifestyle and clinical characteristics

\begin{tabular}{|c|c|c|c|c|}
\hline \multirow[b]{3}{*}{ Age (years), median (IQR) } & \multicolumn{4}{|c|}{ Dialysis } \\
\hline & \multicolumn{2}{|c|}{$\mathrm{HD}(n=58)$} & \multicolumn{2}{|c|}{$\mathrm{PD}(n=31)$} \\
\hline & 65 & $(59-76)$ & 49 & $(39-60)$ \\
\hline \multicolumn{5}{|l|}{ Gender } \\
\hline Men & 31 & $(53.4)$ & 16 & $(51.6)$ \\
\hline Women & 27 & $(46.6)$ & 15 & $(48.4)$ \\
\hline \multicolumn{5}{|l|}{ Education } \\
\hline Primary & 8 & $(14.5)$ & 3 & $(11.5)$ \\
\hline Secondary & 35 & $(63.6)$ & 19 & $(73.1)$ \\
\hline University & 12 & $(21.8)$ & 4 & $(15.4)$ \\
\hline \multicolumn{5}{|l|}{ Smoking of tobacco } \\
\hline Non-smoker & 24 & $(42.9)$ & 16 & $(61.5)$ \\
\hline Ex-smoker & 27 & $(48.2)$ & 6 & $(23.1)$ \\
\hline Current smoker & 5 & $(8.9)$ & 4 & $(15.4)$ \\
\hline Alcohol consumption & 8 & $(14.8)$ & 8 & $(29.6)$ \\
\hline Body mass index $\left(\mathrm{kg} / \mathrm{m}^{2}\right)$, median (IQR) & 25 & $(22-29)$ & 26 & $(22-28)$ \\
\hline Diabetes mellitus & 24 & $(41.4)$ & 8 & $(26.7)$ \\
\hline Duration of diabetes mellitus, median (IQR) & 11 & $(7-16)$ & 12 & $(9-23)$ \\
\hline HbA1c, median (IQR) & 6.2 & $(5.9-6.7)$ & 6.1 & $(5.8-6.9)$ \\
\hline Arterial hypertension & 48 & $(82.8)$ & 30 & $(100.0)$ \\
\hline Duration of dialysis (months); median (IQR) & 36 & $(13-73)$ & 12 & $(8-27)$ \\
\hline \multicolumn{5}{|l|}{ Dry mouth } \\
\hline No & 24 & $(42.9)$ & 13 & $(48.1)$ \\
\hline Periodically & 23 & $(41.1)$ & 10 & $(37.0)$ \\
\hline Permanently & 9 & $(16.1)$ & 4 & $(14.8)$ \\
\hline \multicolumn{5}{|l|}{ Number of tooth-brushing episodes daily } \\
\hline Do not brush & 3 & $(5.4)$ & 0 & $(0.0)$ \\
\hline 1 & 14 & $(25.0)$ & 10 & $(37.0)$ \\
\hline 2 & 30 & $(53.6)$ & 13 & $(48.1)$ \\
\hline$\geq 3$ & 9 & $(16.1)$ & 4 & $(14.8)$ \\
\hline Usage of an interdental brush/floss & 15 & $(26.8)$ & 8 & $(29.6)$ \\
\hline \multicolumn{5}{|l|}{ The last visit to the dentist } \\
\hline within the last year & 31 & $(60.8)$ & 18 & $(72.0)$ \\
\hline $2-3$ years ago & 13 & $(25.5)$ & 5 & $(20.0)$ \\
\hline$\geq 4$ years ago & 7 & $(13.7)$ & 2 & $(8.0)$ \\
\hline Bleeding gums & 5 & $(8.9)$ & 7 & $(26.9)$ \\
\hline Number of teeth, median (IQR) & 16 & $(9-20)$ & 23 & $(17-28$ \\
\hline \multicolumn{5}{|l|}{ Antihypertensive therapy } \\
\hline Angiotensin-converting enzyme inhibitors & 17 & $(30.4)$ & 3 & $(13.0)$ \\
\hline Beta-blockers & 38 & $(67.9)$ & 12 & $(52.2)$ \\
\hline Calcium channel blockers & 27 & $(48.2)$ & 11 & $(47.8)$ \\
\hline Angiotensin II AT1-receptor blockers & 10 & $(17.9)$ & 1 & $(4.8)$ \\
\hline Central $\mathrm{a}-2$ receptor agents & 10 & $(17.9)$ & 11 & $(47.8)$ \\
\hline$a_{1}$-adrenoceptor antagonists & 22 & $(39.3)$ & 3 & $(13.0)$ \\
\hline Antiplatelet therapy & 13 & $(23.2)$ & 5 & $(21.7)$ \\
\hline
\end{tabular}


Table 1 Patients' sociodemographic, vital, lifestyle and clinical characteristics (Continued)

\begin{tabular}{|c|c|c|}
\hline \multirow[b]{3}{*}{ Immunosuppressive therapy } & \multicolumn{2}{|l|}{ Dialysis } \\
\hline & $\mathrm{HD}(n=58)$ & $\mathrm{PD}(n=31)$ \\
\hline & (3.6) & (7.7) \\
\hline
\end{tabular}

\section{Discussion}

This study confirmed the hypothesis that PD is associated with a smaller PISA than HD, indicating a smaller inflammatory burden, independent of a large number of sociodemographic, lifestyle, laboratory and clinical factors. This

Table 2 Laboratory parameters; only patients with complete data were included ( $n=65$; patients with missing data, $n=24$ $(27 \%)$

\begin{tabular}{|c|c|c|c|c|}
\hline \multirow[b]{3}{*}{$\mathrm{Kt} / \mathrm{N}$} & \multicolumn{4}{|c|}{ Dialysis } \\
\hline & \multicolumn{2}{|c|}{$\mathrm{HD}(n=58)$} & \multicolumn{2}{|c|}{$\mathrm{PD}(n=31)$} \\
\hline & 1.4 & $(1.3-1.5)$ & 1.9 & $(1.8-2.1)$ \\
\hline Parathyroid hormone (pmol/L) & 243 & $(100-428)$ & 32 & $(19-80)$ \\
\hline C-reactive protein (mg/L) & 4.8 & $(2.0-14.1)$ & 1.6 & $(0.8-3.4)$ \\
\hline Thrombocytes $\left(10^{9} / \mathrm{L}\right)$ & 180 & $(141-209)$ & 240 & $(183-326)$ \\
\hline Potassium (mmol/L) & 4.7 & $(4.1-5.1)$ & 4.5 & $(4.1-4.7)$ \\
\hline Mean corpuscular volume (fL) & 94 & $(92-96)$ & 91 & $(88-93)$ \\
\hline Leukocytes $\left(10^{9} / \mathrm{L}\right)$ & 6.0 & $(5.1-7.8)$ & 7.3 & $(6.2-8.9)$ \\
\hline Total cholesterol (mmol/L) & 4.1 & $(3.6-4.9)$ & 4.9 & $(3.9-6.1)$ \\
\hline HDL cholesterol (mmol/L) & 1.1 & $(0.9-1.4)$ & 1.5 & $(1.0-1.9)$ \\
\hline Erythrocytes $\left(10^{12} / \mathrm{L}\right)$ & 3.5 & $(3.1-3.7)$ & 3.7 & $(3.3-4.1)$ \\
\hline Creatinine $(\mu \mathrm{mol} / \mathrm{L})$ & 712 & $(614-814)$ & 786 & $(655-893)$ \\
\hline Phosphorus (mmol/L) & 1.5 & $(1.3-1.8)$ & 1.6 & $(1.4-1.9)$ \\
\hline Triglycerides (mmol/L) & 1.4 & $(0.9-2.1)$ & 1.7 & $(1.1-2.7)$ \\
\hline Urea (mmol/L) & 19.8 & $(15.8-22.4)$ & 21.0 & $(17.4-25.4)$ \\
\hline Serum albumin (g/L) & 38 & $(36-40)$ & 39 & $(37-40)$ \\
\hline Sodium (mmol/L) & 136 & $(134-138)$ & 138 & $(134-139)$ \\
\hline Alkaline phosphatase (g) & 79 & $(64-108)$ & 89 & $(69-112)$ \\
\hline Haematocrit (L/L) & 0.33 & $(0.30-0.35)$ & 0.34 & $(0.31-0.36)$ \\
\hline LDL cholesterol (mmol/L) & 2.3 & $(1.7-2.9)$ & 2.6 & $(1.5-3.6)$ \\
\hline Haemoglobin (g/L) & 111 & $(101-117)$ & 109 & $(101-117)$ \\
\hline
\end{tabular}

Data are presented as the median (interquartile range) if not stated otherwise Data were missing for erythrocytes in $2(2.2 \%)$, haemoglobin in $2(2.2 \%)$, haematocrit in $20(22.5 \%)$, mean corpuscular volume in $2(2.2 \%)$, leukocytes in $13(14.6 \%)$, thrombocytes in $2(2.2 \%)$, urea in $3(3.4 \%)$, creatinine in $3(3.4 \%)$, $\mathrm{Kt} / \mathrm{V}$ in $15(16.9 \%)$, C-reactive protein in $4(4.5 \%)$, albumin in $4(4.5 \%)$, total cholesterol in $10(11.2 \%)$, HDL cholesterol in $10(11.2 \%)$, LDL cholesterol in 10 $(11.2 \%)$, triglycerides in $10(11.2 \%)$, potassium in $2(2.2 \%)$, sodium in 19 (21.3\%), phosphorus in $3(3.4 \%)$, alkaline phosphatase in $19(21.3 \%)$, and parathyroid hormone in 8 (9.0\%) participants

Abbreviations: Kt $/ N$ Dialysis adequacy measured as the ratio between dialyser clearance $(\mathrm{K})(\mathrm{mL} / \mathrm{min})$ multiplied by time in minutes $(\mathrm{t})$ and volume of water a patient's body contains; HDL High density lipoprotein cholesterol, LDL Low density lipoprotein cholesterol result may be due to the fact that HD is better for the removal of small-molecular-weight molecules, such as urea and creatinine, which are not real uremic toxins (Kt/ $\mathrm{V}$ is higher in patients on HD than in patients on PD), and that PD is better for the removal of mid-sized molecules (uremic toxins). Uremic toxins can lower the capacity of the immune system [16-18], which may result in a better immune response and healthier periodontal tissue in PD patients. As all dialysis patients are potential organ recipients, it is of upmost importance that there is no hidden source of inflammation prior to kidney transplantation. A meta-analysis published in 2016 [19] also reported that pretransplant dialysis influences short- and long-term complications after kidney transplantation and that PD may be a better choice of pretransplant dialysis modality than HD.

This study also showed the degree of inflammatory burden in Croatian dialysis patients presented by PISA. After adjusting for all confounders, the mean PISA was $798 \mathrm{~mm}^{2}$ in the HD group and $52 \mathrm{~mm}^{2}$ in the PD group. According to the PISA cut-off values defined by the Centers for Disease Control and Prevention-American Academy of Periodontology for the classification of periodontitis, i.e., that severe periodontitis ranges from $934,71 \mathrm{~mm}^{2}$ to $3274,96 \mathrm{~mm}^{2}$, moderate periodontitis ranges from 521,58 to $790,30 \mathrm{~mm}^{2}$, mild periodontitis ranges from 110,16 and $447,01 \mathrm{~mm}^{2}$, and no periodontitis corresponds to PISA values from $10.22 \mathrm{~mm}^{2}$ to $62.78 \mathrm{~mm}^{2}$ [20], periodontal treatment is highly needed among dialysis patients in Croatia.

To our knowledge, this is the first study to measure or compare PISA in CKD patients on HD and PD. Some previous studies have compared other periodontal indices among patients on HD and PD. Crosssectional studies conducted in Brazil, Canada, Turkey, USA and Taiwan have reported that chronic severe periodontitis is significantly more prevalent among patients on HD than among healthy persons, and periodontal disease is comparatively more prevalent and more severe in CKD patients [21-25]. However, PISA provides important advantages over these other periodontal indices. It represents a classification that quantifies the amount of inflamed periodontal tissue and, as such, quantifies the systemic inflammatory burden [7, 12]. 
Table 3 Robust regression on PISA; variables were simultaneously input; only patients with complete data were included

\begin{tabular}{|c|c|c|c|c|c|c|c|}
\hline & $b$ & B & $\mathrm{t}$ & $\mathrm{p}$ & $\mathrm{FDR}<5 \%$ & $r$ & $\mathrm{sr}$ \\
\hline \multicolumn{8}{|l|}{ Dialysis } \\
\hline \multicolumn{8}{|l|}{ HD (referent group) } \\
\hline PD & -526.8 & -0.53 & -2.50 & 0.017 & $\checkmark$ & -0.31 & -0.50 \\
\hline \multicolumn{8}{|l|}{ Confounders that were controlled } \\
\hline Age (years) & -2.0 & -0.05 & -0.47 & 0.644 & & -0.00 & -0.02 \\
\hline Duration of dialysis (months) & -0.3 & -0.03 & -0.18 & 0.856 & & 0.08 & -0.12 \\
\hline Number of teeth & 43.3 & 0.77 & 5.95 & $<0.001$ & $\checkmark$ & 0.52 & 0.74 \\
\hline The last visit to the dentist & -13.4 & -0.11 & -0.99 & 0.327 & & -0.06 & 0.03 \\
\hline \multicolumn{8}{|l|}{ Smoking } \\
\hline \multicolumn{8}{|l|}{ Non-smoker (referent group) } \\
\hline Ex-smoker & 47.3 & 0.10 & 0.33 & 0.744 & & -0.12 & -0.11 \\
\hline Current smoker & 163.7 & & 0.86 & 0.393 & & & \\
\hline Diabetes mellitus & -418.0 & -0.43 & -1.73 & 0.092 & & -0.09 & -0.26 \\
\hline Duration of diabetes mellitus & 27.2 & 0.41 & 1.91 & 0.064 & & -0.08 & 0.32 \\
\hline $\mathrm{HbA} 1 \mathrm{c}^{\mathrm{a}}$ & -44.1 & -0.10 & -0.69 & 0.495 & & -0.14 & -0.04 \\
\hline C-reactive protein (mg/L) & -9.5 & -0.28 & -2.12 & 0.041 & & -0.15 & -0.42 \\
\hline $\mathrm{Kt} / \mathrm{N}$ & -494.5 & -0.36 & -2.20 & 0.034 & $\checkmark$ & -0.21 & -0.28 \\
\hline Thrombocytes $\left(10^{9} / \mathrm{L}\right)$ & -2.2 & -0.35 & -1.80 & 0.081 & & -0.11 & -0.04 \\
\hline Leukocytes $\left(10^{9} / \mathrm{L}\right)$ & 22.5 & 0.12 & 0.78 & 0.442 & & -0.06 & -0.06 \\
\hline Urea (mmol/L) & -4.9 & -0.06 & -0.43 & 0.671 & & 0.03 & -0.15 \\
\hline Phosphorus (mmol/L) & 138.4 & 0.11 & 0.94 & 0.354 & & 0.07 & 0.22 \\
\hline HDL cholesterol (mmol/L) & -61.7 & -0.08 & -0.38 & 0.707 & & -0.07 & 0.01 \\
\hline \multicolumn{8}{|l|}{ Antihypertensive therapy } \\
\hline Beta-blockers & -209.4 & -0.22 & -1.64 & 0.110 & & 0.22 & -0.19 \\
\hline $\begin{array}{l}\text { Angiotensin-converting } \\
\text { Enzyme inhibitors }\end{array}$ & -216.5 & -0.20 & -1.66 & 0.106 & & 0.07 & 0.03 \\
\hline Central a-2 receptor agents & 11.0 & 0.02 & 0.07 & 0.943 & & 0.16 & 0.10 \\
\hline Angiotensin II AT1-receptor blockers & -159.1 & -0.11 & -1.16 & 0.256 & & 0.01 & 0.03 \\
\hline$a_{1}$-adrenoceptor antagonists & -188.5 & -0.18 & -1.47 & 0.151 & & 0.10 & -0.31 \\
\hline
\end{tabular}

Abbreviation: $b$ Unstandardized multivariable robust regression coefficient, $\beta$ Standardized multivariable robust regression coefficient, $t$ Student's t-test statistic with $\mathrm{n}$-p-1 degrees of freedom where $\mathrm{p}$ is total number of parameters in the model, $p$ two-tailed test, statistical significance of multivariable regression coefficient, FDR False discovery rate of $<5 \%$ calculated using the Benjamini-Hochberg method, $r$ zero-order Pearson product-moment correlation with PISA, sr semipartial correlation with PISA after controlling for all other variables, $\mathrm{HbA1c}$ Glycated haemoglobin, Kt/V Dialysis adequacy measured as the ratio between dialyser clearance $(\mathrm{K})(\mathrm{mL} / \mathrm{min})$ multiplied by time in minutes $(\mathrm{t})$ and volume of water a patient's body contains, HDL High-density lipoprotein cholesterol

${ }^{\mathrm{a}} \mathrm{HbA1c}=$ For participants not diagnosed with diabetes, the $\mathrm{HbA} 1 \mathrm{c}$ value was arbitrarily set to 5.0

Previous studies [26] have shown higher levels of periodontitis in patients with CKD than in healthy controls, and the disease is most advanced in maintenance HD patients but successively diminished in PD and pre-dialysis CKD patients.

In 2016, Chinese authors [27] stated that the periodontal status of HD and PD patients was worse than that in healthy controls, but there were no statistically significant differences between the PD and HD groups. However, the average calculus surface index was significantly higher in HD patients than in PD patients. This finding may be related to the alteration in serum phosphorus-calcium in HD patients.
Bayraktar et al. [28] reported a higher gingival index (GI) in the HD group than in the peritoneal group and higher calculus accumulation in both dialysis groups compared with healthy controls. Brito et al. [29] concluded that patients on PD had similar CALs to healthy controls. Moreover, according to Thorman et al. [30], pre-dialysed patients and patients on HD have a higher prevalence of severe periodontitis than healthy controls and patients on PD. Such results can also be explained by the psychological state of patients according to dialysis type and satisfaction with their quality of life. Patients on HD visit the hospital several times a week and are connected to dialysis machines for approximately $4 \mathrm{~h}$. 


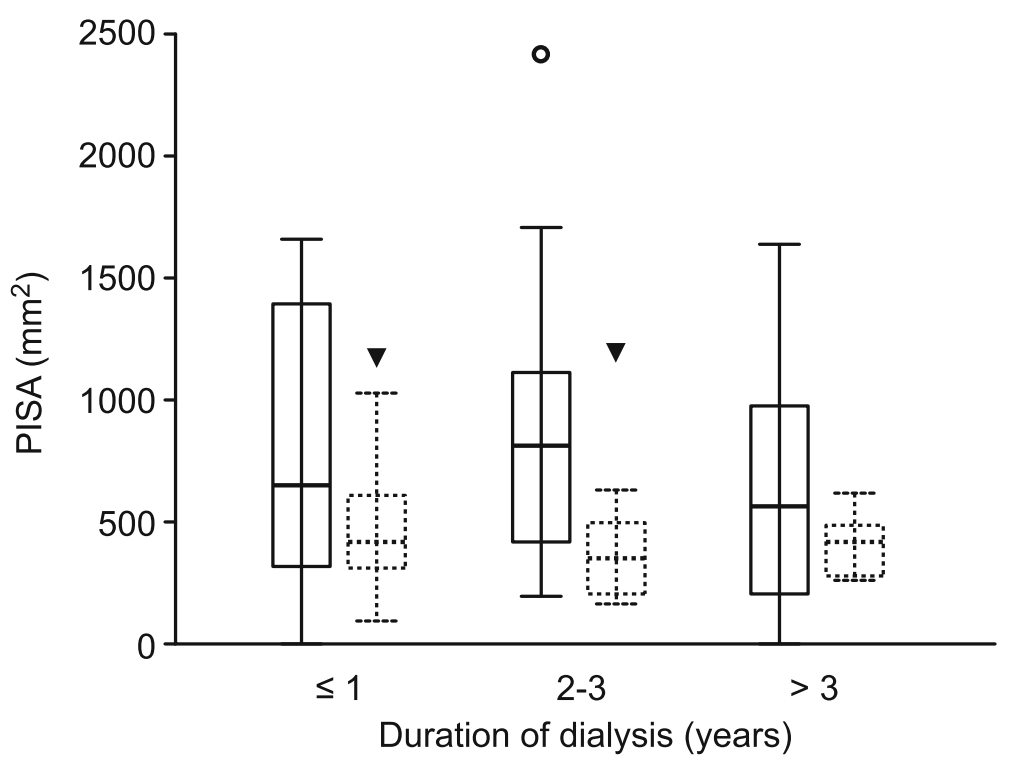

Fig. 2 PISA by the type and duration of dialysis. The solid line represents HD; the dotted line represents PD; the middle line represents the median; the boxes represent the interquartile range; the circle outside the maximum lines represents patients on HD with PISA values larger than the upper quartile plus 1.5 times the interquartile range; the black triangle represents the same for patients on PD; only patients with complete data were included ( $n=65$; patients with missing data, $n=24$ (27\%)

Patients on PD can perform dialysis procedures in their own home or at other clean locations, have more independence and are able to more actively work; and consequently, patients on PD report a better quality of life. In fact, better quality of life and higher satisfaction of patients on PD have been statistically proven by various studies [31, 32]. Some studies have reported high levels of quality of life among patients on PD, although these levels were not statistically significant from the quality of life of other dialysis patients [33-35]. It has been proposed that patients on PD exhibit higher motivation and have a more proactive approach regarding their oral hygiene habits, thus leading to a better periodontal state.

This study did not find significant differences in PISA according to the duration of dialysis in the three groups of patients: those on dialysis for less than a year, for 2-3 years and for more than 3 years. These results are in accordance with the study reported by Parkar and Ajithkrishnan [36], which outlined four subgroups according to the duration of dialysis: less than 3 months, 4-6 months, 7-9 months and 10-12 months. The authors of that study reported no effect of the duration of dialysis on periodontal tissues. A similar study by Marakoglu et al. [37] also revealed no significant differences in age, gingival index, plaque index or periodontal pocket depth among subgroups of patients on HD for less than 1 year, $1-3$ years and more than 3 years. In contrast, Cengiz et al. [38] compared patients on dialysis for less than 5 years, $5-10$ years and more than 10 years and concluded that there were significant increases in plaque index, gingival bleeding and periodontal pocket depth after 5 years and that the difference was statistically more significant after 10 years. These findings suggest that the significant influence of dialysis on periodontal health becomes obvious after 5 years.

\section{Limitations of this study}

The first limitation of this study is that the patients were not randomly allocated to receive HD or PD. An attempt was made to control this source of bias by controlling the effect of a larger number of possible confounders. Nevertheless, we were able to control only the included and known variables, while different important unmeasured factors remained uncontrolled. Periodontal status before the initiation of dialysis and the duration of kidney disease are likely to be highly important factors. The cross-sectional design of this study prevented the observation of a temporal sequence between periodontitis and dialysis, and for this reason, it was not possible to make any causal inferences. Second, patients were enrolled in the specialized nephrology ward of a large university teaching hospital in a highly urban area of the country's capital. It is possible that periodontal disease, dialysis parameters, and their association are different in small, regional hospitals with sparser resources and less educated patients of a lower socioeconomic status. There is no evidence on which to base this claim, but the possibility should be taken into account. Therefore, these findings should not be uncritically generalized to the general Croatian population of patients treated for 
CKD. Third, the primary outcome was not independently assessed, and the participating investigators were not blinded to the type of dialysis. These factors likely induced bias against the null hypothesis. Therefore, these findings are probably somewhat overoptimistic and should be replicated in properly blinded studies. Fourth, the dosages of monitored therapies were not controlled, whereas only whether or not the patient was treated with a particular drug was monitored. Fifth, a consecutive sample of patients was selected, which might have increased the risk of selection bias.

\section{Conclusions}

Patients on PD and HD in Croatia have poor periodontal conditions, presenting high PISA values, and require periodontal treatment. PD is associated with a smaller PISA independent of many sociodemographic, lifestyle, laboratory and clinical factors. No relationship between the duration of dialysis and PISA was found. A prospective, randomized, control study is needed to test for a causal relationship.

\section{Supplementary information}

Supplementary information accompanies this paper at https://doi.org/10. 1186/s12903-020-01086-7.

Additional file 1. Oral hygiene habits, alcohol consumption and

smoking habits questionnaire

\section{Abbreviations}

PD: Peritoneal dialysis; HD: Haemodialysis; PISA: Periodontal inflamed surface area; CKD: Chronic kidney disease; eGFR: Estimated glomerular filtration rate; ESRD: End-stage renal disease; CAL: Clinical attachment level; REC: Recession; BOP: Bleeding on probing; ALSA: Attachment loss surface area; REC: Recession surface area; PESA: Periodontal epithelial surface area; HDL: High-density lipoprotein; LDL: Low-density lipoprotein; FDR: False discovery rate; IQR: Interquartile range; Kt/N: Fractional urea clearance; HbA1c: Glycated haemoglobin

\section{Acknowledgements}

The authors wish to acknowledge the work of all patients, physicians and medical nurses who participated in data collection.

\section{Authors' contributions}

BKS participated in the study design, carried out all periodontal examinations, collected the clinical data and wrote the manuscript; KA designed the nephrological aspect of the study, helped with collection of the clinical data, and supervised renal patient recruitment; MK and NBJ facilitated renal patient recruitment and offered scientific advice in the field of their expertise; AA designed the periodontal aspect of the study and supervised this clinical study and the writing of the manuscript. All authors reviewed and approved the draft manuscript.

\section{Funding}

Not applicable.

\section{Availability of data and materials}

All data generated from this study are available from the corresponding author upon reasonable request.

\section{Ethics approval and consent to participate}

1. Approved 11/06/2014, Ethics Committee University Hospital Center "Sestre Milosrdnice" (Vinogradska cesta 29, HR-10000, Zagreb, Croatia; + 385 13787111), ref.: EP-7326/14-11

2. Approved 12/02/2015, Ethics Committee School of Dental Medicine, University of Zagreb (Gunduliceva 5, HR-10000 Zagreb, Croatia), ref.: 05-PA26-6/2015

All patients gave written informed consent for participation.

\section{Consent for publication}

Not applicable.

\section{Competing interests}

The authors declare that they have no competing interests to declare.

\section{Author details}

${ }^{1}$ Department of Endodontics with Restorative Dentistry, Oral Medicine and Periodontology, Dental Clinic Zagreb, Perkovčeva ulica 3, 10000 Zagreb, Croatia. ${ }^{2}$ Clinic of Internal Medicine, University Hospital Center "Sestre milosrdnice", Vinogradska cesta 29, 10000 Zagreb, Croatia. ${ }^{3}$ Clinic of Internal Medicine, University Hospital Center Merkur, Zajčeva ulica, 10000 Zagreb, Croatia. ${ }^{4}$ Clinic of Internal Medicine, University Hospital Center Zagreb, Kišpatićeva ulica 12, 10000 Zagreb, Croatia. ${ }^{5}$ Department of Periodontology, School of Dental Medicine, University of Zagreb, Gundulićeva ulica 5, 10000 Zagreb, Croatia

Received: 7 September 2019 Accepted: 25 March 2020 Published online: 03 April 2020

\section{References}

1. Levey AS, Eckardt KU, Tsukamoto Y, Levin A, Coresh J, Rossert J, et al. Definition and classification of chronic kidney disease: a position statement from kidney disease: improving global outcomes (KDIGO). Kidney Int. 2005; 67:2089-100.

2. Blake PG, Quinn RR, Oliver MJ. Peritoneal dialysis and the process of modality selection. Perit Dial Int. 2013;33:233-41.

3. Jain AK, Blake $P$, Cordy $P$, Garg AX. Global trends in rates of peritoneal dialysis. J Am Soc Nephrol. 2012;23:533-44.

4. Garcia Rl, Henshaw MM, Krall EA. Relationship between periodontal disease and systemic health. Periodontol 2000. 2001;25:21-36.

5. Tonetti MS, Jepsen S, Jin L, Otomo-Corgel J. Impact of the global burden of periodontal diseases on health, nutrition and wellbeing of mankind: a call for global action. J Clin Periodontol. 2017;44:456-62.

6. Seymour GJ, Ford PJ, Cullinan MP, Leishman S, Yamazaki K. Relationship between periodontal infections and systemic disease. Clin Microbiol Infect. 2007:13:3-10.

7. Nesse W, Abbas F, van der Ploeg I, Spijkervet FK, Dijkstra PU, Vissink A. Periodontal inflamed surface area: quantifying inflammatory burden. J Clin Periodontol. 2008;35:668-73.

8. Chambrone L, Foz AM, Guglielmetti MR, Pannuti CM, Artese HP, Feres M, et al. Periodontitis and chronic kidney disease: a systematic review of the association of diseases and the effect of periodontal treatment on estimated glomerular filtration rate. J Clin Periodontol. 2013;40:443-56.

9. Loos BG. Systemic markers of inflammation in periodontitis. J Periodontol. 2005:76:2106-15.

10. Deschamps-Lenhardt S, Martin-Cabezas R, Hannedouche T, Huck O Association between periodontitis and chronic kidney disease: systematic review and meta-analysis. Oral Dis. 2019;25:385-402.

11. Akar H, Akar GC, Carrero JJ, Stenvinkel P, Lindholm B. Systemic consequences of poor oral health in chronic kidney disease patients. Clin J Am Soc Nephrol. 2011;6:218-26.

12. Park SY, Ahn S, Lee JT, Yun PY, Lee YJ, Lee JY, et al. Periodontal inflamed surface area as a novel numerical variable describing periodontal conditions. J Periodontal Implant Sci. 2017:47:328-38.

13. World Medical Association. World medical association declaration of Helsinki: ethical principles for medical research involving human subjects. JAMA. 2013;310:2191-4.

14. Hujoel PP, White BA, Garcia RI, Listgarten MA. The dentogingival epithelial surface area revisited. J Periodontal Res. 2001;36:48-55.

15. R Development Core Team. R: a language and environment for statistical computing. Vienna: R Foundation for Statistical Computing; 2008. 
16. Kato S, Chmielewski M, Honda H, Pecoits-Filho R, Matsuo S, Yuzawa Y, et al. Aspects of immune dysfunction in end-stage renal disease. Clin J Am Soc Nephrol. 2008;3:1526-33.

17. Cohen G, Hörl WH. Immune dysfunction in uremia-an update. Toxins (Basel). 2012;4:962-90.

18. Massy ZA, Liabeuf S. Middle-molecule uremic toxins and outcomes in chronic kidney disease. Contrib Nephrol. 2017;191:8-17.

19. Tang $M, L i T$, Liu H. A comparison of transplant outcomes in peritoneal and hemodialysis patients: a meta-analysis. Blood Purif. 2016;42:170-6.

20. Leira Y, Martin-Lancharro P, Blanco J. Periodontal inflamed surface area and periodontal case definition classification. Acta Odontol Scand. 2018;76:1958.

21. Souza CR, Liberio SA, Guerra RN, Monteiro S, Silveira EJ, Pereira AL. Assessment of periodontal condition of kidney patients in hemodialysis. Rev Assoc Med Bras. 2005:51:285-9.

22. Craig RG. Interactions between chronic renal disease and periodontal disease. Oral Dis. 2008;14:1-7.

23. Klassen JT, Krasko BM. The dental health status of dialysis patients. J Can Dent Assoc. 2002;68:34-8.

24. Duran I, Erdemir EO. Periodontal treatment needs of patients with renal disease receiving haemodialysis. Int Dent J. 2004;54:274-8.

25. Chen LP, Chiang CK, Chan CP, Hung KY, Huang CS. Does periodontitis reflect inflammation and malnutrition status in hemodialysis patients? Am J Kidney Dis. 2006;47:815-22.

26. Borawski J, Wilczynska-Borawska M, Stokowska W, Mysliwiec M. The periodontal status of pre-dialysis chronic kidney disease and maintenance dialysis patients. Nephrol Dial Transplant. 2007;22:457-64.

27. Ma L, Jin X, Cao Y, Xu Z, Xing S, Xu B. Periodontal status of patients undergoing peritoneal dialysis or hemodialysis. Int J Clin Exp Med. 2016;9: 16759-64.

28. Bayraktar G, Kurtulus I, Kazancioglu R, Bayramgurler I, Cintan S, Bural C, et al. Evaluation of periodontal parameters in patients undergoing peritoneal dialysis or hemodialysis. Oral Dis. 2008;14:185-9.

29. Brito F, Almeida S, Figueredo CM, Bregman R, Suassuna JH, Fischer RG Extent and severity of chronic periodontitis in chronic kidney disease patients. J Periodontal Res. 2012;47:426-30.

30. Thorman R, Neovius M, Hylander B. Clinical findings in oral health during progression of chronic kidney disease to end-stage renal disease in a Swedish population. Scand J Urol Nephrol. 2009:43:154-9.

31. Makkar V, Kumar M, Mahajan R, Khaira NS. Comparison of outcomes and quality of life between hemodialysis and peritoneal dialysis patients in Indian ESRD population. J Clin Diagn Res. 2015;9:0C28-31.

32. Al Wakeel J, Al Harbi A, Bayoumi M, Al-Suwaida K, Al Ghonaim M, Mishkiry A. Quality of life in hemodialysis and peritoneal dialysis patients in Saudi Arabia. Ann Saudi Med. 2012;32:570-4.

33. Okpechi IG, Nthite T, Swanepoel CR. Health-related quality of life in patients on hemodialysis and peritoneal dialysis. Saudi J Kidney Dis Transpl. 2013;24: 519-26.

34. de Abreu MM, Walker DR, Sesso RC, Ferraz MB. Health-related quality of life of patients recieving hemodialysis and peritoneal dialysis in Sao Paulo, Brazil: a longitudinal study. Value Health. 2011;14:S119-21.

35. Wright $L S$, Wilson $L$. Quality of life and self-efficacy in three dialysis modalities: incenter hemodialysis, home hemodialysis, and home peritoneal dialysis. Nephrol Nurs J. 2015;42:463-76 quiz 77.

36. Parkar SM, Ajithkrishnan CG. Periodontal status in patients undergoing hemodialysis. Indian J Nephrol. 2012;22:246-50.

37. Marakoglu I, Gursoy UK, Demirer S, Sezer H. Periodontal status of chronic renal failure patients receiving hemodialysis. Yonsei Med J. 2003;44:648-52.

38. Cengiz Ml, Sumer P, Cengiz S, Yavuz U. The effect of the duration of the dialysis in hemodialysis patients on dental and periodontal findings. Oral Dis. 2009;15:336-41.

\section{Publisher's Note}

Springer Nature remains neutral with regard to jurisdictional claims in published maps and institutional affiliations.

Ready to submit your research? Choose BMC and benefit from:
- fast, convenient online submission
- thorough peer review by experienced researchers in your field
- rapid publication on acceptance
- support for research data, including large and complex data types
- gold Open Access which fosters wider collaboration and increased citations
- maximum visibility for your research: over 100M website views per year
At BMC, research is always in progress.
Learn more biomedcentral.com/submissions

